\title{
Evaluation of Fungicides against Myrothecium roridum Causing Leaf Spot of Soybean under in vitro Conditions
}

\author{
Meghchand Dewangan*, Arvind Kumar Kurre, Sandeep Kumar Pandey and \\ Upendra Kumar Nag
}

\author{
Department of Plant Pathology, Indira Gandhi Krishi Vishwavidyalaya, Raipur - 492 001, \\ Chhattisgarh, India \\ *Corresponding author
}

\section{A B S T R A C T}

\begin{tabular}{|c|}
\hline Keywords \\
\hline $\begin{array}{l}\text { Myrothecium } \\
\text { leaf spot, } \\
\text { Soybean, } \\
\text { Myrothecium } \\
\text { roridum, } \\
\text { Fungicides. }\end{array}$ \\
\hline Article Info \\
\hline $\begin{array}{l}\text { Accepted: } \\
\text { 19 June } 2017 \\
\text { Available Online: } \\
\text { 10 August } 2017\end{array}$ \\
\hline
\end{tabular}

Myrothecium leaf spot of soybean caused by Myrothecium roridum. Myrothecium leaf spot of soybean is occurring in almost all the major soybean growing areas of India causing about 30 per cent yield loss. Initial symptoms of the disease appear as small round or oval, brown spots with dark brown margin on leaves in the infected plant. Since it is an economically important disease, management of the disease plays crucial role. Poisoned food technique was employed for the evaluation of fungicides in the laboratory. Six fungicides viz. Dithan M45 (Mancozeb75\%WP), Hexaconazole 5SC (Contaf), Propiconazole 25EC (Tilt), Tebuconazole 250EC (Folicur), Pyraclostrobin, Fluxapyroxd were evaluated against $M$. roridum. Two concentrations i.e., $50 \mathrm{ppm}, 100 \mathrm{ppm}$, of each treatment were used. In this study, in vitro evaluation of six fungicides at two concentrations (50 and $100 \mathrm{ppm}$ ) showed that Propiconazole, and Pyraclostrobin most effective in inhibiting the mycelia growth of $M$. roridum.

\section{Introduction}

Soybean (Glycine max. L. Merril) belonging to family Leguminaceae is designated as miracle bean established its potential as an industrially vital and viable oilseed crop in many areas of India. Leaf spot of soybean caused by Myrothecium roridum Tode ex. Fries is an important disease, which occurred in epidemic proportion entailing into colossal losses to soybean crop in Madhya Pradesh (Shrivastava and Khan, 1994, Singh and Shrivastava, 1994). Myrothecium leaf spot of soybean is occurring in almost all the major soybean growing areas of India causing about 30 per cent yield loss (Shrivastava and Khan 1994). The disease severity of myrothecium leaf spot soybean was in the range of 35 to 45 $\%$ and disease incidence of myrothecium leaf spot soybean was in the range of 30 to $55 \%$ (Singh and Shrivastava, 1994). Myrothecium roridum is ordinary soil fungi, and survive in this environment as saprophytes in decaying plant tissues (Ellis, 1971).Initial symptoms of the disease appear as small round or oval, brown spots with dark brown margin on leaves in the infected plant. Since it is an economically important disease, management of the disease plays crucial role. Duval et al., (2010) tested some fungicides in vitro against an isolate of $M$. roridum. Talukar et al., (2013) tested seven fungicides at three 
concentrations (250, 500 and $1000 \mathrm{ppm})$ under in-vitro condition against $M$. roridum. There are numerous reports on fungicides in vitro condition to control the disease.

\section{Materials and Methods}

\section{Experimental site}

The laboratory experiment was carried out at Department of Plant Pathology, IGAU, Raipur (C.G.).

\section{Isolation of test fungus}

The fresh infected leaves of soybean plant samples were cut into small pieces, surface sterilized with $0.1 \%$ mercuric chloride $\left(\mathrm{HgCl}_{2}\right)$ solution followed by three washing with sterile distilled water and placing in moist chamber than after 1 to 2 days fungal mycelium growth were seen than finally small bits of fungus kept on the previously poured and solidified potato dextrose agar medium in Petri plates for isolation of the pathogen. The plates were incubated at $25^{\circ} \mathrm{C}$ in $\mathrm{BOD}$ incubator.

\section{In vitro evaluation of fungicides}

Poisoned food technique was employed for the evaluation of fungicides in the laboratory. Six fungicides viz. Dithan M45 (Mancozeb 75\% WP), Hexaconazole 5SC (Contaf), Propiconazole 25EC (Tilt), Tebuconazole 250EC (Folicur), Pyraclostrobin, Fluxapyroxad were evaluated against $M$. roridum. Two concentrations i.e., $50 \mathrm{ppm}$, $100 \mathrm{ppm}$, of each treatment were used. The required quantity of fungicide was mixed with PDA at the time of pouring. Three replications were maintained for each fungicide for each of its concentration in Complete Randomized Design (CRD). The media was shaken well so as to enhance proper mixing of the fungicides. To avoid bacterial contamination a little amount of streptomycin was added in each flask before plating; five mm disc was cut with the help of sterilized cork borer from seven days old culture of the test fungus and was placed in the center of the medium in the reversed position to maintain continuous contact of the pathogen with poisoned medium. PDA plates without fungicide served as control. The radial growth of the colony was measured when the growth in control plates reached the rim of the Petri plates. Percent growth inhibition under the influence of different fungicides was calculated on the basis of the control. Observation was recorded at 10 days and 15 days after inoculation.

Percent inhibition of radial growth were calculated by the following

Inhibition $\%=\mathrm{C}-\mathrm{T} / \mathrm{C} \times 100$

Whereas

$\mathrm{C}=$ Diameter of fungus colony $(\mathrm{mm})$ in control plate,

$\mathrm{T}=$ Diameter of fungus colony $(\mathrm{mm})$ in treated plate

\section{Results and Discussion}

\section{In vitro evaluation of fungicides}

Data in table 1 indicates that all fungicides were significantly superior in reducing the mycelial growth in comparison to control. In $50 \mathrm{ppm}$ concentration percent growth inhibition of $M$. roridum recorded ranged between $100 \%$ to $62.33 \%$ in at 10DAI while it was $100 \%$ to $63.33 \%$ in 15 DAI. Complete inhibition of mycelial growth was recorded in the propiconazole and pyraclostrobin $(100 \%)$ at $10 \mathrm{DAI}$ as well as $15 \mathrm{DAI}$. The minimum inhibition was recorded at 10 DAI in the Mencozeb (62.33\%) followed by 
Fluxapyroxad (64.25\%), Hexaconazole $(66.66 \%)$ and Tebuconazole $(83.33 \%)$. The minimum inhibition was recorded at 15 DAI in the Mencozeb (63.33\%) followed by Fluxapyroxad (66.11\%), Hexaconazole $(68.75 \%)$ and Tebuconazole $(85.12 \%)$.

In $100 \mathrm{ppm}$ concentration all fungicides were significantly superior in reducing the mycelial growth over control at $10 \mathrm{DAI}$ and $15 \mathrm{DAI}$ (Table 1; Plates 1 and 2). Percent inhibition in growth of $M$. roridum recorded in ranged $100 \%$ to $81.11 \%$ in 10 DAI and $100 \%$ to $73.70 \%$ in 15DAI. Complete inhibition of mycelia growth was recorded in the Propiconazole and Pyraclostrobin (100\%) at 10 DAI as well as 15DAI (Figs. 1 and 2).

Plate.1 Effect of different fungicides on radial growth of Myrothecium roridum (50ppm)

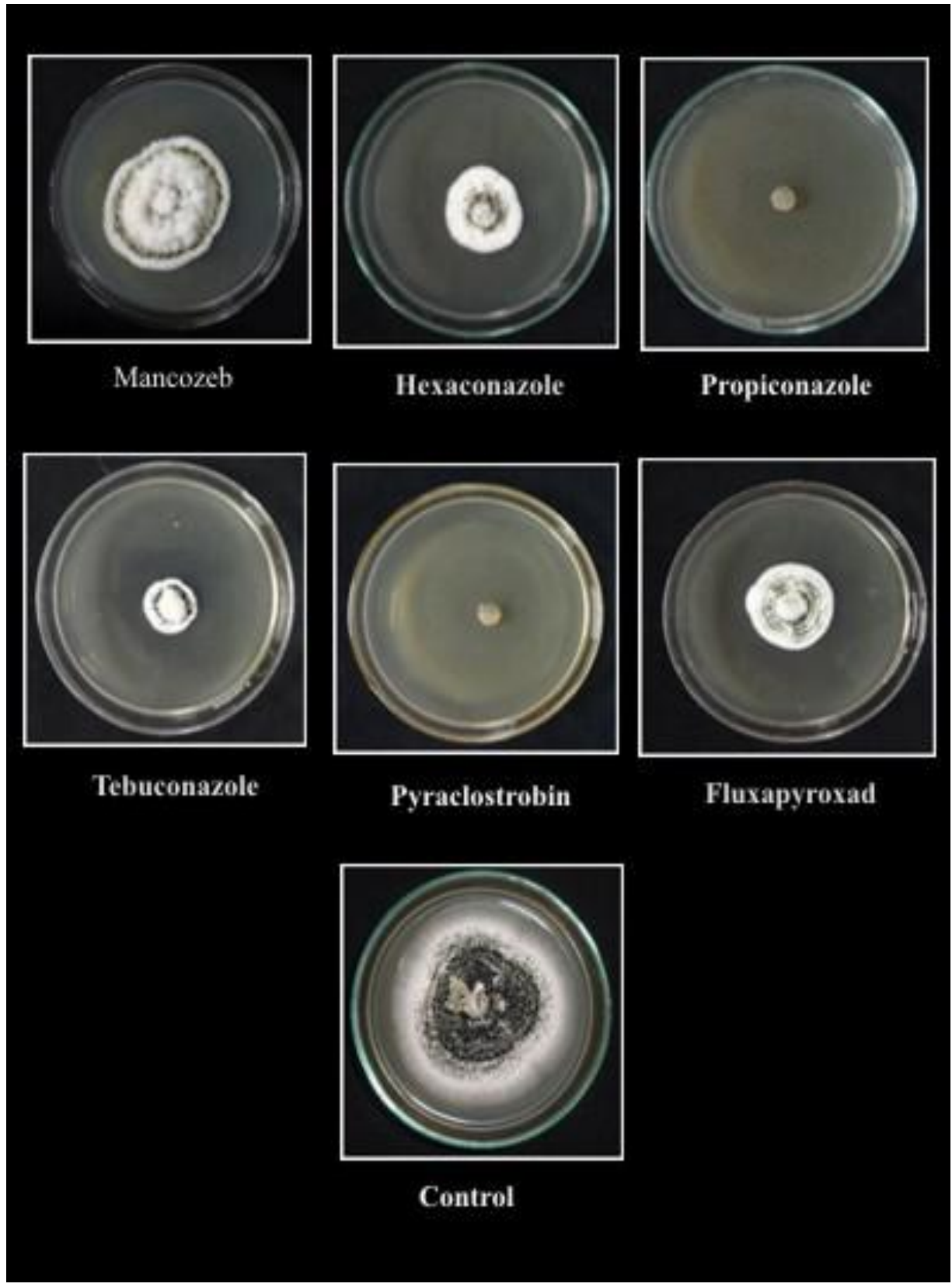


Plate.2 Effect of different fungicides on radial growth of Myrothecium roridum (100ppm)

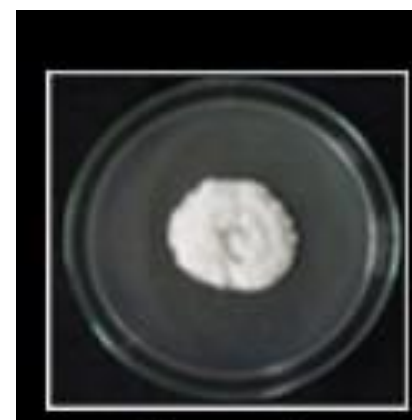

Mancozeb

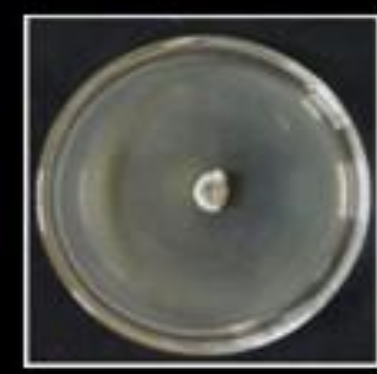

Tebuconazole

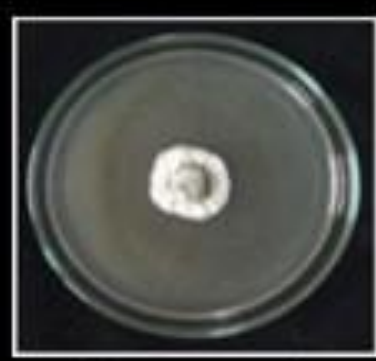

Hexaconazole

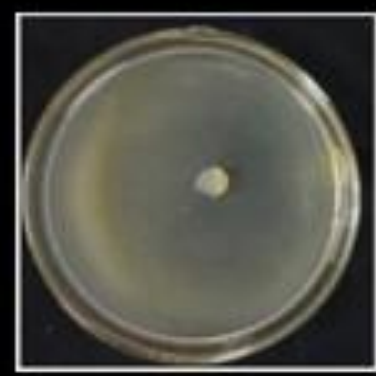

Pyraclostrobin

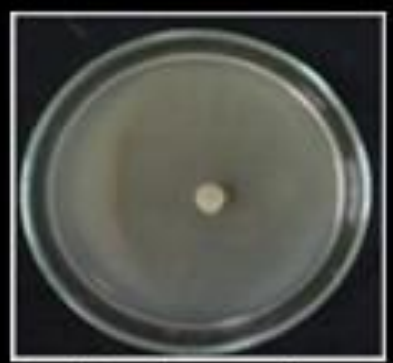

Propiconazole

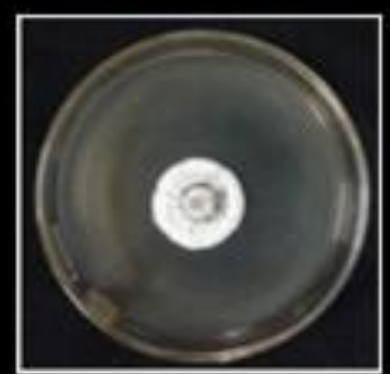

Fluxapyroxad

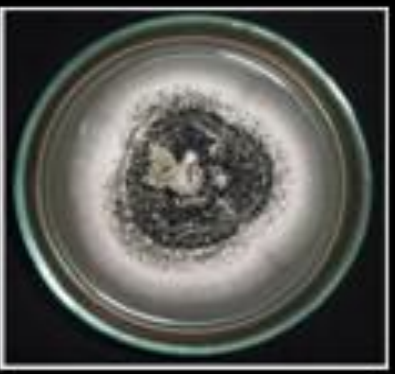

Control

Table.1 Effect of different fungicides on radial growth of Myrothecium roridum 50ppm and 100ppm

\begin{tabular}{|c|c|c|c|c|c|c|c|c|c|}
\hline \multirow[t]{3}{*}{ S. N. } & \multirow[t]{3}{*}{ Fungicides } & \multicolumn{8}{|c|}{ Radial growth (mm) } \\
\hline & & \multicolumn{2}{|c|}{$10 \mathrm{DAI} * *(50 \mathrm{ppm})$} & \multicolumn{2}{|c|}{$15 \mathrm{DAI}$} & \multicolumn{2}{|c|}{10 DAI (100ppm) } & \multicolumn{2}{|c|}{$15 \mathrm{DAI}$} \\
\hline & & $\mathrm{G}(\mathrm{mm})^{*}$ & $\mathrm{I}(\%)$ & $\mathrm{G}(\mathrm{mm})^{*}$ & $\mathrm{I}(\%)$ & $\mathrm{G}(\mathrm{mm})^{*}$ & $\mathrm{I}(\%)$ & $\mathrm{G}(\mathrm{mm}) *$ & $\mathrm{I}(\%)$ \\
\hline 1 & Mencozeb & 22.66 & 62.23 & 29.33 & 63.33 & 11.33 & 81.11 & 22.00 & 73.70 \\
\hline 2 & Hexaconazole & 20.00 & 66.66 & 25.00 & 68.75 & 10.00 & 83.33 & 20.00 & 76.09 \\
\hline 3 & Propiconazole & 0.00 & 100.00 & 0.000 & 100.00 & 0.00 & 100.00 & 0.00 & 100.00 \\
\hline 4 & Tebuconazole & 10.00 & 83.33 & 12.00 & 85.12 & 8.00 & 86.66 & 9.00 & 89.24 \\
\hline 5 & Pyraclostrobin & 0.00 & 100.00 & 0.00 & 100.00 & 0.00 & 100.00 & 0.00 & 100.00 \\
\hline 6 & Fluxapyroxad & 21.33 & 64.45 & 27.33 & 66.11 & 11.00 & 82.71 & 21.66 & 74.10 \\
\hline \multirow[t]{3}{*}{7} & Control & 60.00 & & 80.66 & & 60.000 & & 83.66 & \\
\hline & $\mathrm{CD}(5 \%)$ & 1.726 & & 1.158 & & 0.668 & & 2.471 & \\
\hline & $\mathrm{SE}(\mathrm{m})$ & 0.563 & & 0.378 & & 0.218 & & 0.807 & \\
\hline
\end{tabular}

* Means of three replications ** Days after inoculation, G- Growth, I- Inhibition 
Fig.1 Effect of different fungicides on radial growth of Myrothecium roridum (50ppm)

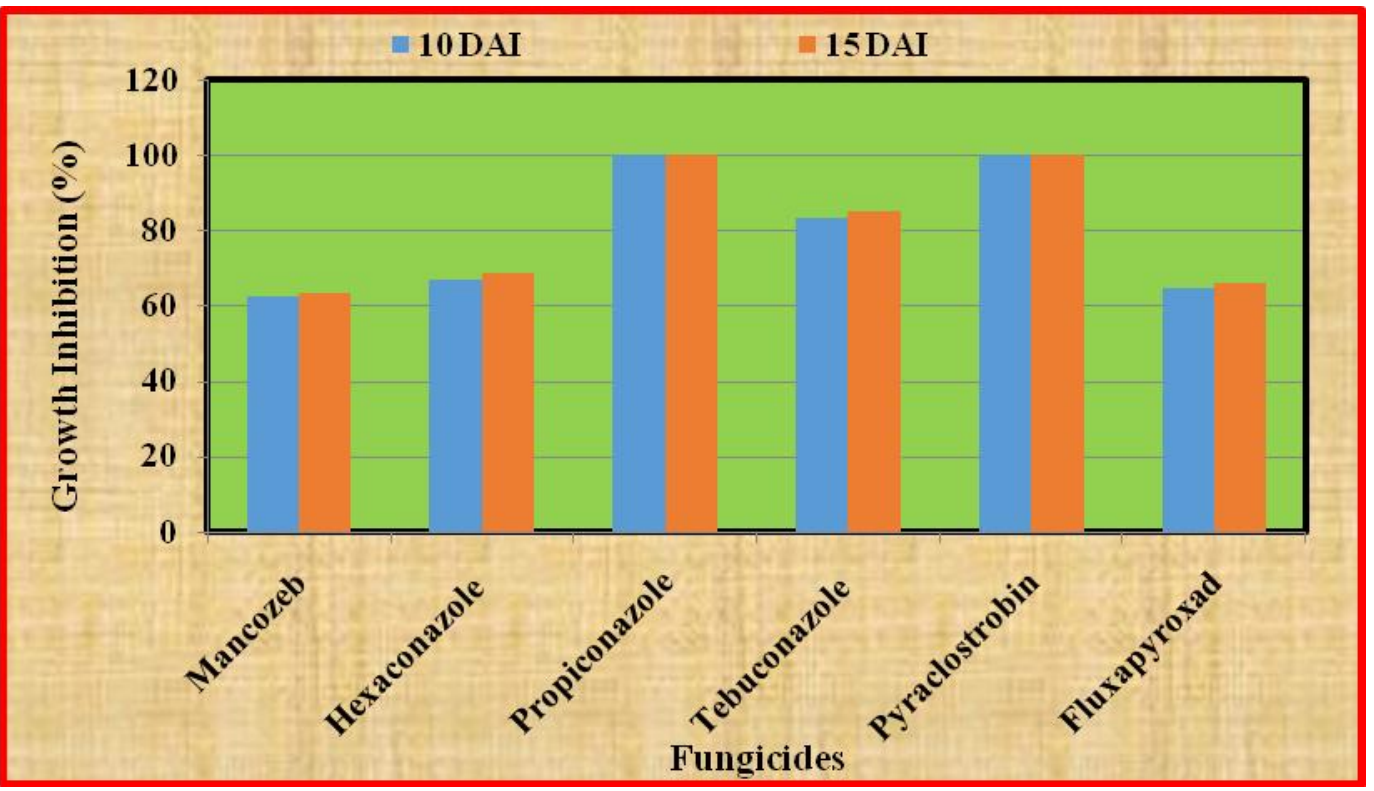

Fig.2 Effect of different fungicides on radial growth of Myrothecium roridum (100ppm)

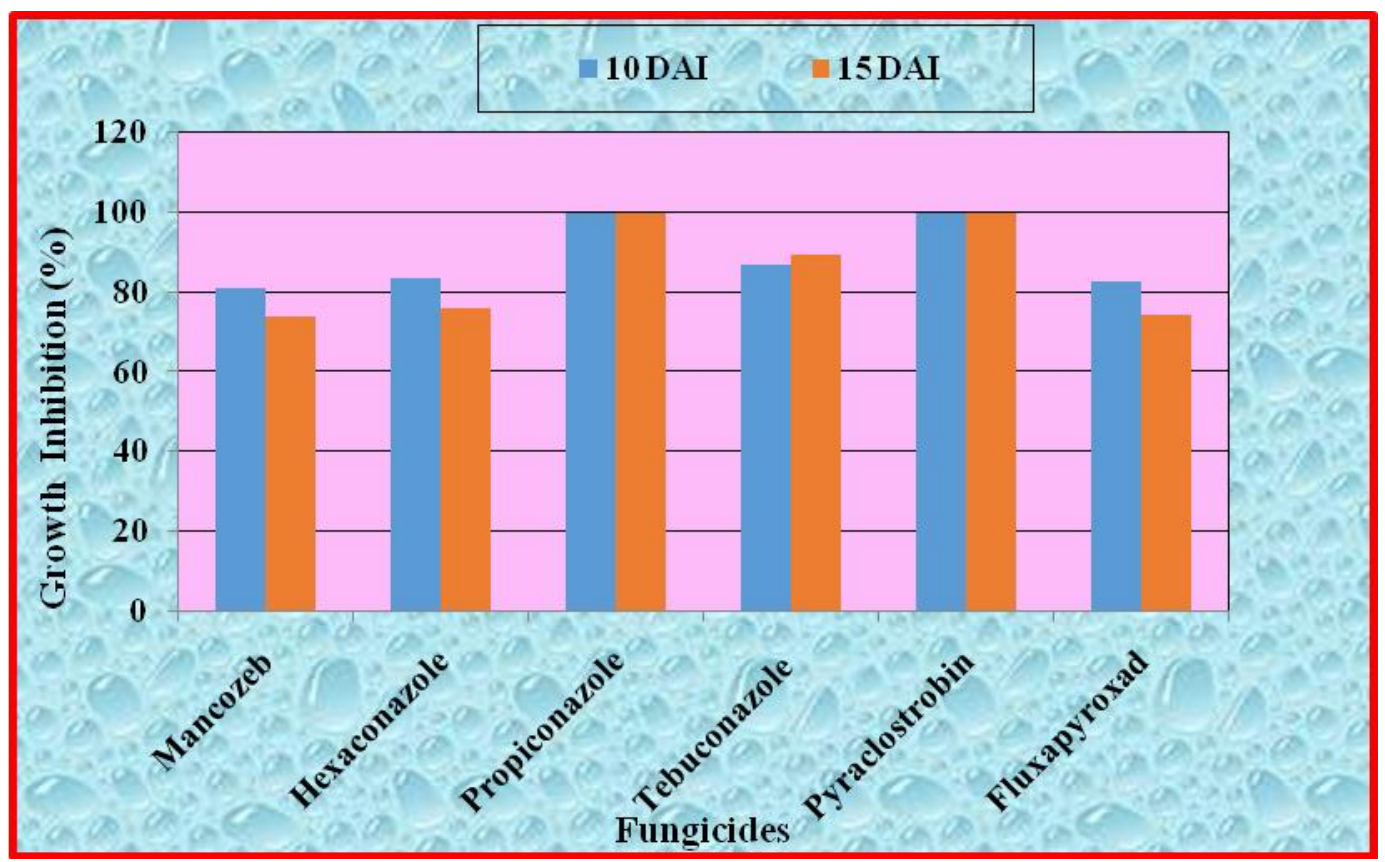

The minimum inhibition was recorded at 10 DAI in the Mencozeb (81.11. \%) followed by Fluxapyroxad (82.71\%) Hexaconazole $(83.33 \%)$ and Tebuconazole (86.66. \%), the minimum inhibition was recorded at 15 DAI in the Mencozeb (73.70\%) followed by Fluxapyroxad (74.10\%), Hexaconazole
$(76.09 \%)$ and Tebuconazole $(89.24 \%)$ Similarly, Duval et al., (2010) reported that the fungicide Tebuconazole (85.50\%) highly effective in inhibiting the mycelial growth of Myrothecium roridum. Kale and Ukesh (2015) reported the fungicides Propiconazole and Hexaconazole as best in maximum 
inhibition against $M$. roridum. Daivasikamani et al., (2013) reported the mycelia growth of M. roridum by Tebuconazole $(90.10 \%)$ and Propiconazole $(83.9 \%)$.

In conclusion, the present study in evaluation of fungicides against Myrothecium roridum causing leaf spot of eoybean under in vitro conditions result showed Propiconazole, Pyraclostrobin and Tebuconazole were very effective in two (50 ppm and $100 \mathrm{ppm}$ ) concentrations in reducing mycelia growth of $M$. roridu under lab conditions.

\section{References}

Daivasikamani, S., Singh, S., Ranjini, A.P., Sudhakar, S. and Jayarama (2013).Screening of fungicides against Myrothecium roridum causing stem necrosis and leaf spot disease of coffee seedlings. J. Coffee Res. 41(1\&2): 92 101 .
Duval, A.M.Q., Henz, G.P., Lima, P.M.L., Medeiros, A.R., Miranda, B.E.C., fenning, L.H. and Reis, A. 2010. New hosts of Myrothecium spp. in Brazil and a preliminary in vitro assay of fungicides. Brazilian Journal of Microbiology, 41(1): 246-252.

Ellis, M.B. (1971). Dematiaceous Hyphomycetes. Kew. CMI.

Kale, P.A. and Ukesh, C. 2015. In Vitro Evolution of Fungicides and Bioagent against Soybean Plant Pathogens. IJSRE, vol. 3(1): 2772-2777.

Shrivastava, S.K. and Khan, S.U (1994). Impact of host age at infection time on the severity of Myrothecium leaf spot disease of soybean. Indian Phytopatho, 47(2): 190-191.

Singh, S.M. and Shrivastava, S.K. (1994). Screening of soybean varieties against leaf spot disease caused by Myrothecium roridum. Indian Journal of Mycology and Plant Pathology, 24(3): 222.

\section{How to cite this article:}

Meghchand Dewangan, Arvind Kumar Kurre, Sandeep Kumar Pandey and Upendra Kumar Nag. 2017. Evaluation of Fungicides against Myrothecium roridum Causing Leaf Spot of Soybean under in vitro Conditions. Int.J.Curr.Microbiol.App.Sci. 6(8): 1953-1958. doi: https://doi.org/10.20546/ijcmas.2017.608.231 